\title{
IN-PLANE STATIC RESPONSE OF DRY-JOINT MASONRY ARCH-PIER STRUCTURES
}

\author{
Bora Pulatsu ${ }^{1}$, Ece Erdogmus ${ }^{2}$, Eduardo M. Bretas ${ }^{3}$ and Paulo B. Lourenço ${ }^{4}$ \\ ${ }^{1}$ Graduate Research Assistant, Architectural Engineering, University of Nebraska-Lincoln, 242 \\ Peter Kiewit Institute, 1110 South 67 ${ }^{\text {th }}$ St. Omaha, NE 68131; e-mail: bpulatsu2@unl.edu \\ ${ }^{2}$ Professor, Architectural Engineering, University of Nebraska-Lincoln, 203C Peter Kiewit \\ Institute, 1110 South 67 ${ }^{\text {th }}$ St. Omaha,NE 68131; e-mail: eerdogmus@unl.edu \\ ${ }^{3}$ Senior Research Scientist, Department of Infrastructure, Materials and Structures, Northern \\ Research Institute, Narvik, Norway; e-mail: eduardo@tek.norut.no \\ ${ }^{4}$ Professor, Institute for Sustainability and Innovation in Structural Engineering, University of \\ Minho, Guimaraes, Portugal; e-mail:pbl@civil.uminho.pt
}

\begin{abstract}
The majority of historical masonry structures include arches and vaults, constructed with or without (dry-joint) any mortar. This paper focuses on dry-joint masonry, because it is common all around the world among architectural heritage. Furthermore, even if there was a mortar in the original construction, it typically suffers from deterioration over its lifetime, often causing total loss of mortar in many of the joints.

Due to large horizontal thrust that can be produced, depending on their geometry, arches are typically supported by heavy buttresses. These structures tend to be difficult to model due to their nonlinear nature and inherent discontinuity, which makes it challenging to evaluate their stability. In that context, it is necessary to have realistic numerical models to better diagnose their structural behaviour in a seismic event and, ultimately, to perform only necessary and beneficial interventions. The main goal of this paper is to assess the seismic performance of various dry-joint arch forms with different masonry pier types (i.e. monolithic and regularly coursed) subjected to incrementally increasing lateral loads proportional to the mass (pushover). To achieve this goal, a parametric study is performed on arch curvature and pier morphology. Moreover, the influence of steel tie-rod reinforcement is also examined on the proposed masonry models.

These complex masonry arch systems can be simulated with discrete element modeling (DEM) approach. In this research, a commercial three-dimensional discrete element code, 3DEC, is used; in which masonry units are modeled as distinct blocks with zero tensile strength at their joints. The results reveal that pointed arches provide better seismic resistance than the circular arch form. Furthermore, implemented steel tie-rods yield significant increase in stability for the arch-pier structures, which is quantified on different arch curvatures.
\end{abstract}

Keywords: Arch-Pier Structures, Collapse mechanism, DEM, Pushover, Steel-ties

\section{INTRODUCTION}


- This is a pre-print version of an article published in Pulatsu B., Erdogmus E., Bretas E.M. and Lourenço P.B. (2019) In-Plane Static Response of Dry-Joint Masonry Arch-Pier Structures, Architectural Engineering Institute (AEI) Conference, April 3-6. DOI: 10.1061/9780784482261.028

Through the history of construction techniques, masonry has a special place among all other materials. There are many examples where the vast capabilities of masonry structures have been demonstrated around the world. This heterogeneous and complex construction material provides various benefits both from artistic and structural engineering point of view. The high compression strength, high durability, low maintenance cost and pleasing aesthetics are just some of the common advantages of masonry constructions. However, it has been a challenge to model historic masonry structures due to its composite and nonlinear nature. Several numerical modeling strategies are available depending on the desired level of accuracy and computational cost. Each method has its own limitations and should be selected according to the essential purpose of the analysis. Lourenço (2002) summarizes the various modeling techniques for masonry in three main categories: micro-, simplified micro-, and macro modeling.

In present research, the discrete element method (DEM), which is a discontinuum approach and falls into the simplified micro modeling strategy, is used to simulate masonry arch-pier structures. Several fundamental features of DEM among others are listed below.

- In DEM, rather than seeking for continuity conditions at the nodes (e.g. standard finite element procedure), each block is taken into consideration, individually. The interaction between rigid and/or deformable bodies are simulated via point contact approach.

- Large displacements, contact openings and sliding failures may be obtained at the discontinuities through numerical solutions.

- Implemented contact detection algorithm provides new contact recognition and contact status update, automatically.

The inherent nature of DEM is appropriate to replicate masonry structures that are composed blocky elements. The detailed explanation of applied numerical methodology and analyzed masonry structures are discussed in the next sections.

\section{NUMERICAL PROCEDURE}

The formulation of DEM differs from continuum-based methods, considering the contacts between the distinct bodies making up the discontinuous system (Cundall and Hart 1993). Since early 1990s, DEM has been actively employed to assess the strength and behavior of masonry structures as an alternative approach to the well-known homogenized continuum-based numerical models, (Dimitri 2011, Lemos 2007, Pulatsu 2018, Pulatsu 2019). In the present study, DEM is utilized to evaluate the in-plane response of masonry arch-pier structures (frames) subject to horizontal static loads with/without steel tie reinforcement. Rigid and deformable blocks are used to represent masonry units. Joints are modeled as zero thickness interfaces.

In three-dimensional (3D) space, the dynamic solution scheme of DEM relies on the integration of equations of motion using explicit finite difference algorithm. The deformable blocks are generated by sub-dividing them into constant strain triangular (CST) zones and different constitutive material behavior may be considered. Static solutions are obtained by adaptive damping, which is similar to the classical dynamic relaxation methods. The action/reaction forces between blocks are encountered through sub-contacts via linear/nonlinear springs located at each contact points. Soft contact approach is applied where penetration of one block to another is allowed and calculated at each time step. The mechanical interactions between blocks are 
- This is a pre-print version of an article published in Pulatsu B., Erdogmus E., Bretas E.M. and Lourenço P.B. (2019) In-Plane Static Response of Dry-Joint Masonry Arch-Pier Structures, Architectural Engineering Institute (AEI) Conference, April 3-6. DOI: 10.1061/9780784482261.028

simulated by point contact approach that provides the calculation of forces depending on the relative displacements between blocks and the contact stiffness in the normal $\left(k_{n}\right)$ and shear $\left(k_{s}\right)$ directions. Therefore, the contact forces are calculated as shown in Equations (1) and (2).

$$
\begin{aligned}
\Delta F_{n} & =k_{n} A_{c} \Delta u_{n} \\
\Delta F_{s} & =k_{s} A_{c} \Delta u_{s}
\end{aligned}
$$

where $\Delta F_{n}, \Delta F_{s}, A_{c}, \Delta u_{n}$ and $\Delta u_{s}$ are the normal contact force, shear contact force, contact area, normal and shear displacements, respectively. The mechanical interaction between blocks are simulated using Coulomb-slip joint model with tension cut-off. Since the main interest of current research is to model dry-joint masonry structures, the tensile strength $\left(f_{t}\right)$ and cohesion $(c)$ are both considered to be zero during the analysis. On the other hand, relatively high friction angle $(\phi)$ is set to the joints to prevent any sliding failure at the contacts (Figure 1). Thus, the contact tensile forces are set to zero once any tensile stress is developed due to external forces.

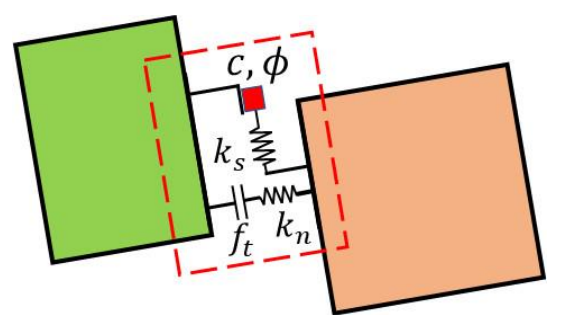

Figure 1. Representation of point contact and corresponding parameters.

In addition, scaled masses are used to improve the convergence of the solutions. The new block positions and velocities are calculated once the law of motions (translational and rotational) are integrated for each block. Then, the contact force-displacement laws are applied to find new contact forces in the system. Finally, calculated force increments are added to the current time step forces and updated according to the assigned failure criteria. The executed calculation cycle is schematized in Figure 2.

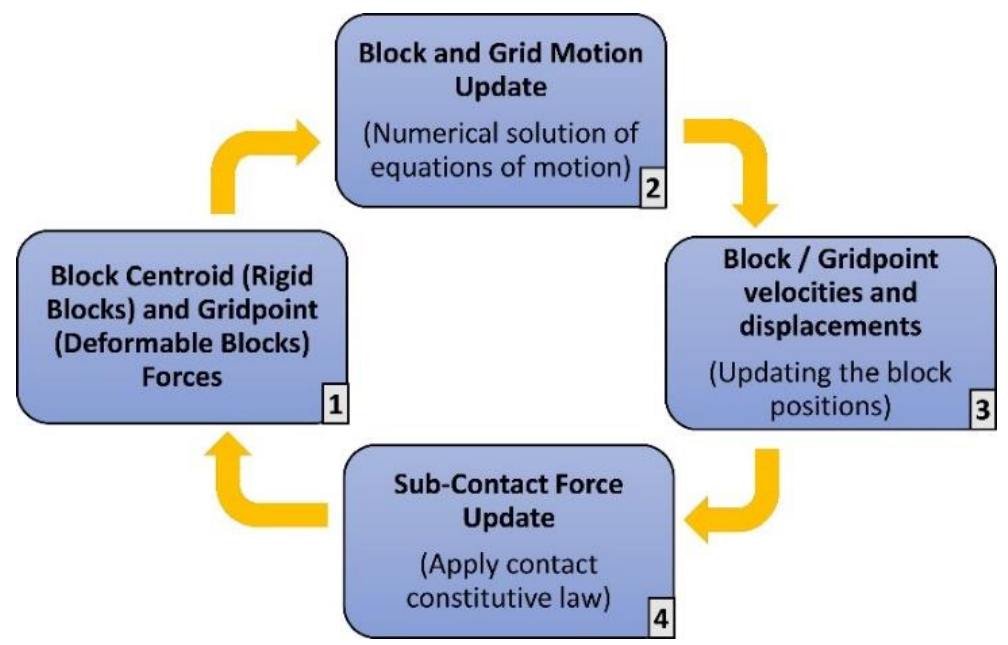

Figure 2. Calculation cycle of DEM 
- This is a pre-print version of an article published in Pulatsu B., Erdogmus E., Bretas E.M. and Lourenço P.B. (2019) In-Plane Static Response of Dry-Joint Masonry Arch-Pier Structures, Architectural Engineering Institute (AEI) Conference, April 3-6. DOI: 10.1061/9780784482261.028

\section{DISCRETE ELEMENT MODELS}

There is a great number of arch styles depending on the artistic and architectural concerns of the era and/or the region. The common arch forms are either circular as seen in the Classical Roman, Romanesque and Renaissance styles, or pointed as seen in the Gothic styles. We also see a variety of arches in more recent history, such as in the Neo-Classical and Neo-Gothic styles, as well as modern masonry construction. In this study, circular and pointed arch geometries with different arch curvatures are selected as representative form of common arch styles.

\section{Geometries}

Since the ancient Roman times, masonry arch design has been a subject of interest for engineers and researchers. Throughout the centuries, there are many empirical rules proposed to calculate the amount of material used (stone, brick etc.) and the safety of structures. In this study, arch thickness to radius ratio $\left(t / R_{C}\right)$ of 0.2 is used for the circular arch models and an identical arch thickness of $40 \mathrm{~cm}$ is considered in all numerical models. In addition, the sharpness of the pointed arches is adjusted by setting a certain amount of eccentricity $(e)$ to the arch form while keeping the arch thickness constant. The representative circular and pointed arch models are shown in Figure 3. Furthermore, two different masonry piers are considered, monolithic and regularly coursed blocks, which is referred as discontinuous pier in this article. The same width $(w)$ and height $(H)$ of the abutment pier is employed in discrete models that has a $w / R_{C}$ ratio of 0.5 and 4 $\mathrm{m}$ height.

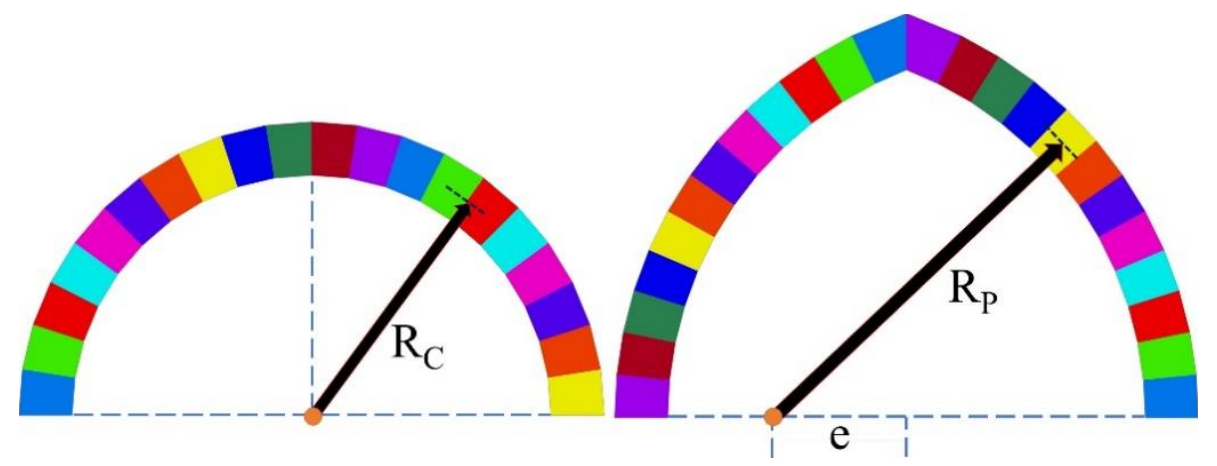

Figure 3. Circular and pointed $\operatorname{arch}$ forms $\left(R_{C}\right.$ : $\operatorname{Radius}$ of circular $\left.\operatorname{arch}\right),\left(R_{P}\right.$ : Radius of point arch).

\section{Material and Contact Properties}

Two separate discrete element models are created that are composed of rigid and deformable blocks. Deformable blocks are essential to implement cable elements that replicate the steel reinforcements. In rigid block model, deformations are lumped at the joints meaning that the displacement capacity of the structure is controlled by the contact stiffnesses and contact inelastic parameters (tensile strength, cohesion $(c)$ and friction angle $(\phi)$ ). In case of deformable blocks, however, deformations of the material (elastic and/or inelastic) also contributes to the deformation of the system. The parametric study on the arch curvature is performed for both rigid and 
- This is a pre-print version of an article published in Pulatsu B., Erdogmus E., Bretas E.M. and Lourenço P.B. (2019) In-Plane Static Response of Dry-Joint Masonry Arch-Pier Structures, Architectural Engineering Institute (AEI) Conference, April 3-6. DOI: 10.1061/9780784482261.028

deformable blocky systems, to provide a comparison of the baselines. The material and contact properties used in this study are given in Table 1, and they follow the suggestions provided in relevant literature (Lengyel 2017, Pulatsu et al. 2016).

Table 1. Material and contact properties

\begin{tabular}{|c|c|c|c|c|}
\hline \multicolumn{5}{|c|}{ Rigid Block Model } \\
\hline$\rho(\mathrm{kg} / \mathrm{m} 3)$ & $k_{n}(\mathrm{~Pa} / \mathrm{m})$ & $k_{s}(\mathrm{~Pa} / \mathrm{m})$ & $\phi\left(^{\circ}\right)$ \\
\hline 2348 & $2 \mathrm{e}+10$ & \multicolumn{2}{c|}{$1 \mathrm{e}+10$} & 40 \\
\hline \multicolumn{5}{|c|}{ Deformable Block Model } \\
\hline$E(\mathrm{kPa})$ & $v(-)$ & $k_{n}(\mathrm{GPa} / \mathrm{m})$ & $k_{s}(\mathrm{GPa} / \mathrm{m})$ & $\phi\left(^{\circ}\right)$ \\
\hline $1.35 \mathrm{e}+7$ & 0.2 & $1 \mathrm{e}+12$ & $1 \mathrm{e}+12$ & 40 \\
\hline
\end{tabular}

\section{ASSESSMENT OF ARCH PIER SYSTEMS}

The stability of the masonry arch-pier structures is examined under an increasing acceleration in the horizontal direction as proportional to the mass (pushover analysis). Similar applications of pushover analysis may be found in (Pena et al. 2010 and Pulatsu et al. 2017, among others). Further, the seismic coefficient, or collapse multiplier $(\xi)$, representing the horizontal ground acceleration that is essential to yield a hinging mechanism is found for all discrete element models. The direction of accelerations and a circular arch with monolithic piers are shown in Figure 4a.

\section{DEM Validation with Limit State Analysis}

To validate the discrete element models used in this study, the results from the numerical analysis of a circular arch with a monolithic pier is compared to the limit analysis solution, proposed by (Alexakis and Makris 2017). Two DEMs, using both rigid and deformable blocks without any reinforcement, are utilized in this validation. The resulting horizontal seismic coefficients indicate a good agreement with the result of the limit state analysis (LSA) as shown in Table 2. There is less than $1 \%$ difference found between LSA and discrete element models. The examined structures developed identical global failure mechanism with 4 plastic hinges where three of them appear at the arch and the fourth hinge forms at the bottom corner of the pier (Figure 4b). In addition, identical hinge locations are found for both rigid and deformable block models, in which collapse mechanism turns into a rigid body motion, progressively.

Table 2. The seismic coefficients $(\xi)$ obtained by LSA and DEM for a circular arch with monolithic pier $(t / R=0.15, b / h=0.25)$

\begin{tabular}{|c|c|c|}
\hline LSA & Rigid Block (DEM) & Deformable Block (DEM) \\
\hline 0.1147 & 0.1152 & 0.1152 \\
\hline
\end{tabular}


- This is a pre-print version of an article published in Pulatsu B., Erdogmus E., Bretas E.M. and Lourenço P.B. (2019) In-Plane Static Response of Dry-Joint Masonry Arch-Pier Structures, Architectural Engineering Institute (AEI) Conference, April 3-6. DOI: 10.1061/9780784482261.028

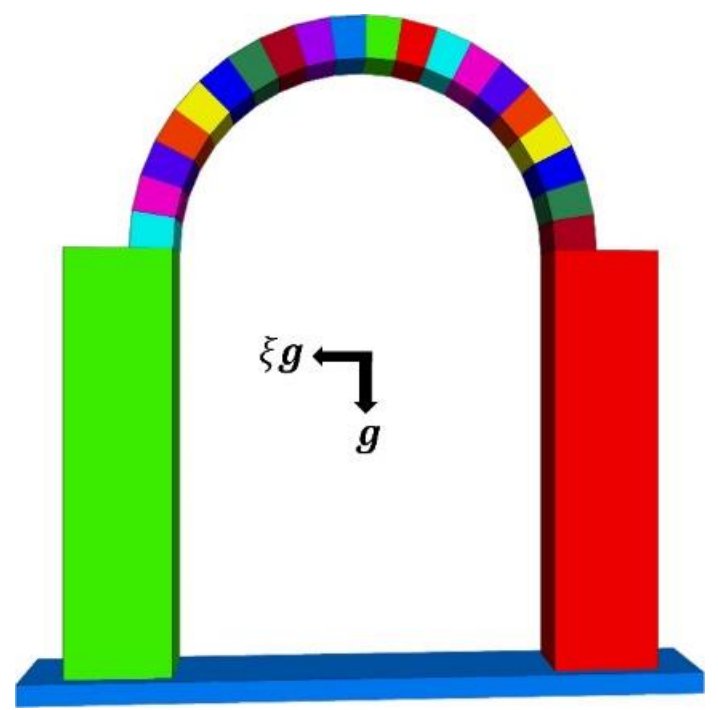

a) DEM model

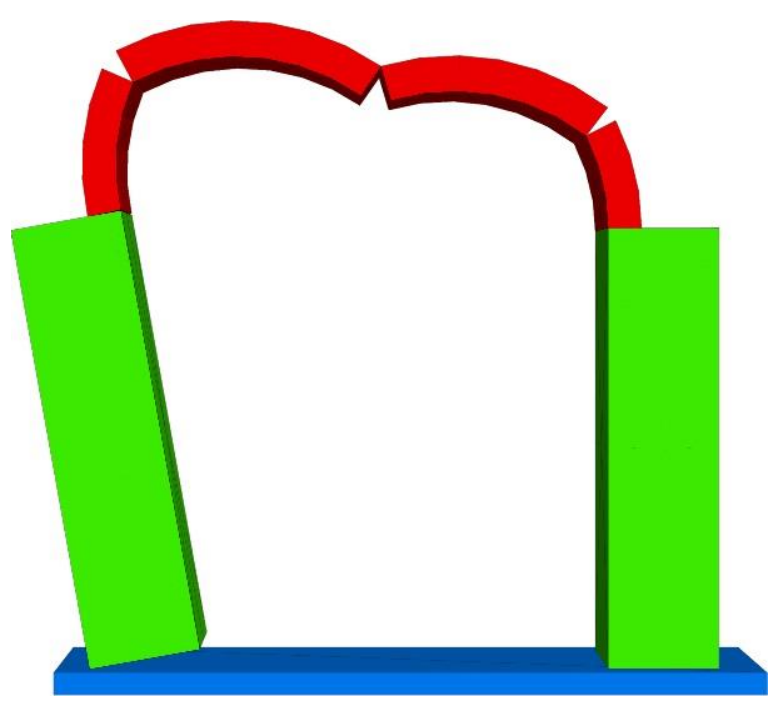

b) Collapse Mechanism

Figure 4. Discrete element model and collapse mechanism under horizontal loads.

\section{Effect of Arch and Pier Geometry on the Behavior of Arch-Pier Structures}

The curvature of an arch directly effects the distribution of the horizontal and vertical forces (the thrust of the vault) developing at the arch-pier connections. It is well-known that the arches with higher curvatures exert less horizontal thrust on the piers, and this in turn affects the design of the buttresses. Here, a parametric analysis is carried out to observe the influence of arch curvature on the seismic resistance and failure modes. Figure 5 indicates the positive contribution of the archcurvature on the overall lateral strength of arch-pier structures for both masonry pier morphologies. (note that an eccentricity $(e)$ equals to zero indicates a circular arch and $(e)$ equals to one indicates a steep pointed arch). However, it is important to note that the regularly coursed masonry pier (discontinuous) caused remarkably less seismic capacity than monolithic column by developing stairway cracks as shown in Figure 6.

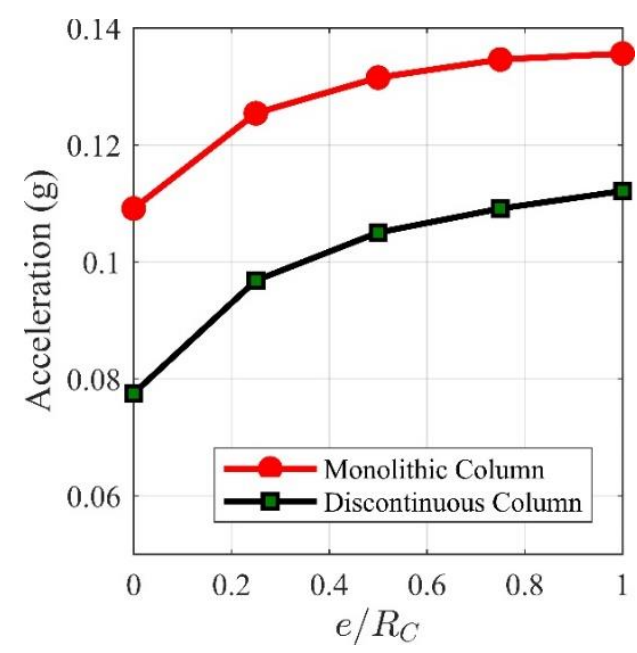

Figure 5. Acceleration vs different arch curvatures for monolithic and discontinuous piers. 
- This is a pre-print version of an article published in Pulatsu B., Erdogmus E., Bretas E.M. and Lourenço P.B. (2019) In-Plane Static Response of Dry-Joint Masonry Arch-Pier Structures, Architectural Engineering Institute (AEI) Conference, April 3-6. DOI: 10.1061/9780784482261.028

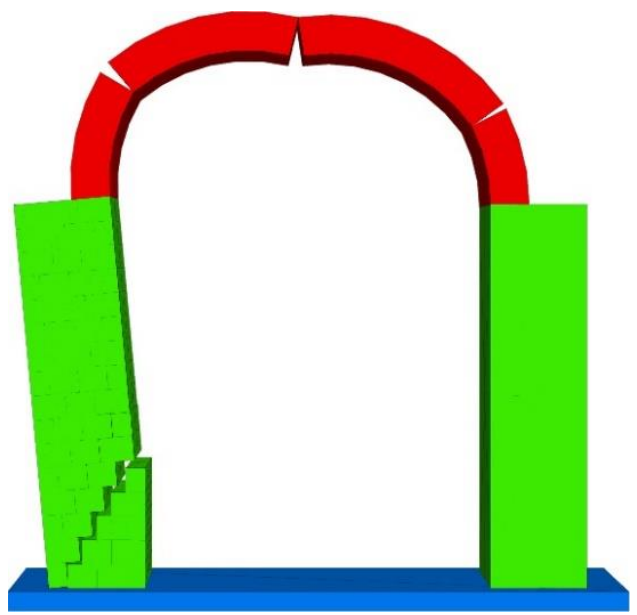

a) Collapse mechanism of circular arch with discontinuous pier under horizontal loads $\left(e / R_{C}: 0\right)$ (4-hinges).

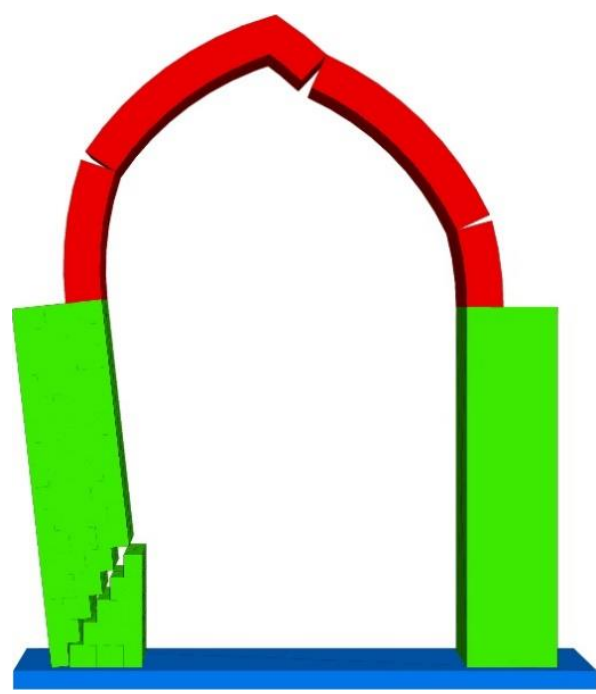

b) Collapse mechanism of pointed arch with discontinuous pier under horizontal loads $\left(e / R_{C}: 0.75\right)$ (4-hinges).

Figure 6. Collapse mechanism of pointed arch with discontinuous piers $\left(e / R_{C}: 0.75\right)$.

\section{Arch-pier structures with steel-tie}

After their baseline behavior is examined under lateral loads and accelerations, the arch-pier models are further studied for the influence of steel tie-rods on their seismic behavior. The implemented strengthening strategy is a widely used solution to overcome excessive horizontal thrusts develop in the vaults, especially in seismic regions. During these analyses, the tie-rods are attached to the springing of the arches and it is assumed that there is no failure at the bond between masonry and tie-rods. The positive influence of reinforcement is pronounced for various arch curvatures with both monolithic and discontinuous masonry piers, as presented in Figure 7. However, due to less horizontal thrust of gothic arches, the seismic capacity is less influenced compared to the circular arch form in that case. 
- This is a pre-print version of an article published in Pulatsu B., Erdogmus E., Bretas E.M. and Lourenço P.B. (2019) In-Plane Static Response of Dry-Joint Masonry Arch-Pier Structures, Architectural Engineering Institute (AEI) Conference, April 3-6. DOI: 10.1061/9780784482261.028

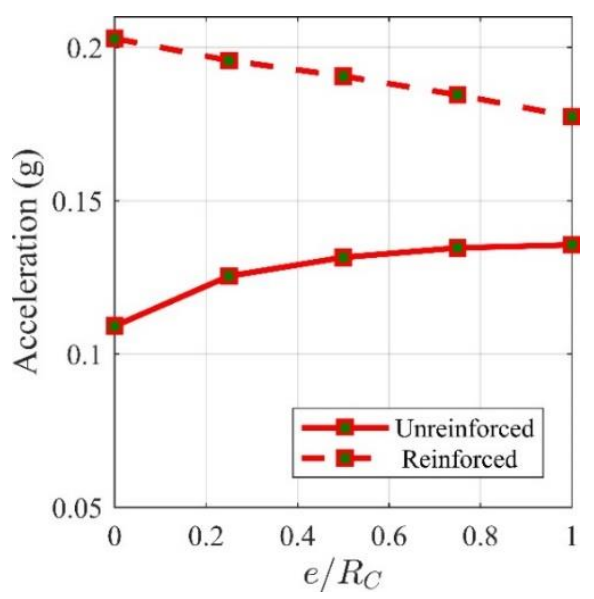

a) Seismic coefficients for arch-monolithic pier structures

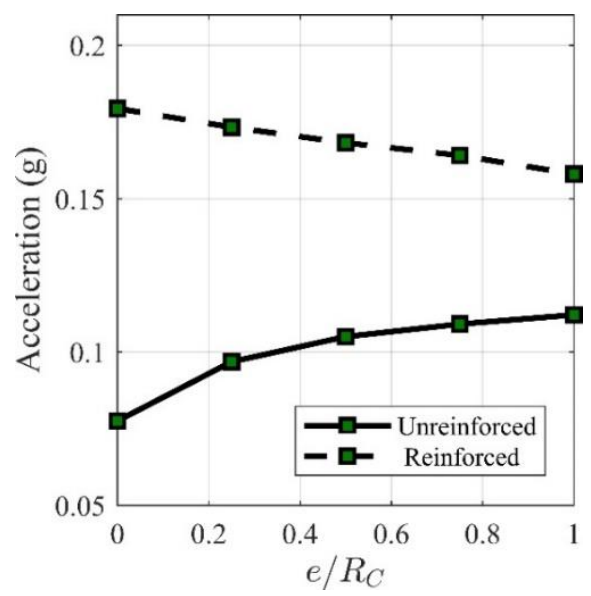

b) Seismic coefficients for arch-discontinuous pier structures

Figure 7. Acceleration vs different arch curvatures for monolithic and discontinuous piers with steel tie.

In addition, the applied reinforcement also changes the collapse mechanism of the arch-pier structures where two piers are involved into collapse mechanism, as shown in Figure 8. Again, the detrimental effect of the fracture at the discontinuous masonry pier is observed, occurring in both piers.

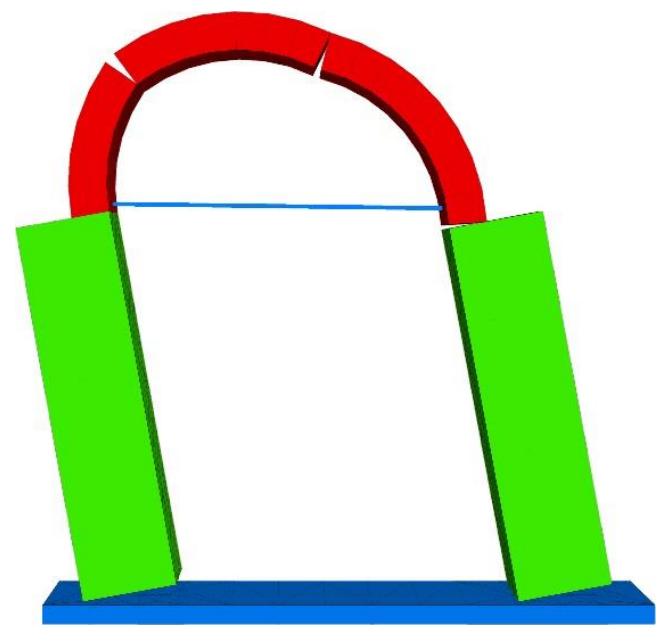

a) Collapse mechanism of circular arch-pier (monolithic) structure with steel-tie (5hinges).

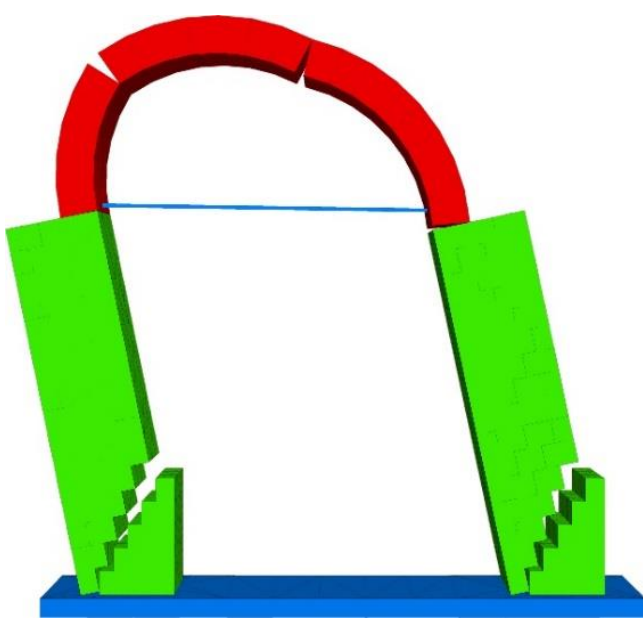

b) Collapse mechanism of circular arch-pier (discontinuous) structure with steel-tie (5hinges). 
- This is a pre-print version of an article published in Pulatsu B., Erdogmus E., Bretas E.M. and Lourenço P.B. (2019) In-Plane Static Response of Dry-Joint Masonry Arch-Pier Structures, Architectural Engineering Institute (AEI) Conference, April 3-6. DOI: 10.1061/9780784482261.028

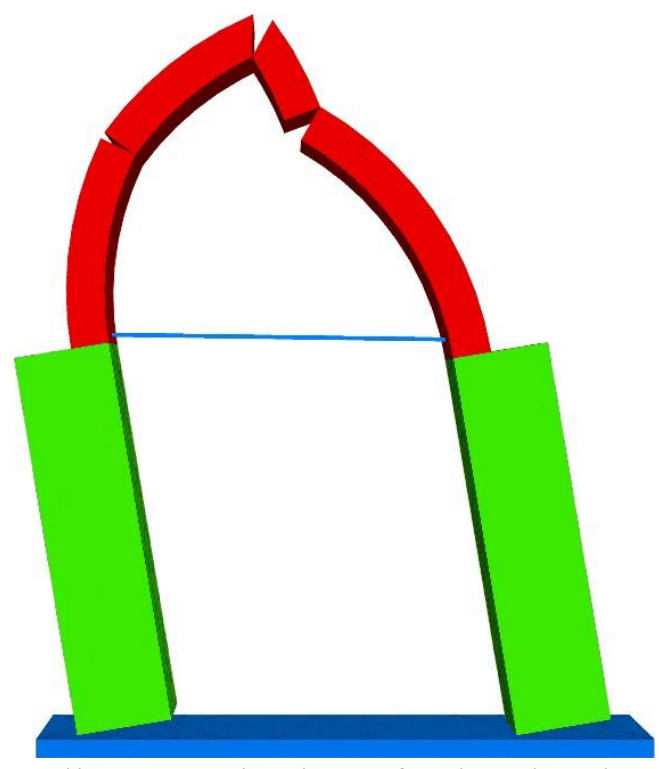

c) Collapse mechanism of pointed arch-pier (monolithic) structure with steel-tie (5hinges).

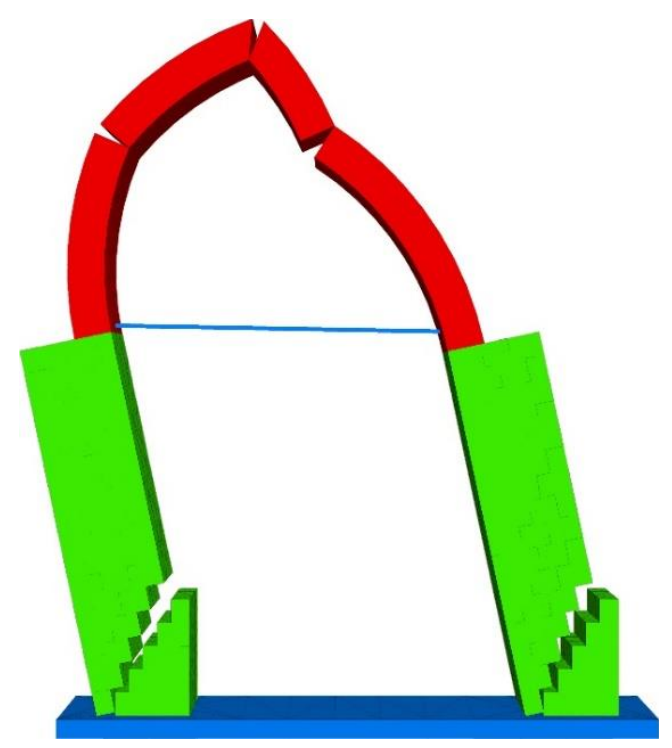

d) Collapse mechanism of pointed arch-pier (discontinuous) structure with steel-tie (5hinges).

Figure 8. Collapse mechanism of various arch-pier structures with steel-tie.

\section{CONCLUSIONS}

This study provides insight on the seismic behavior of arch-pier structures with and without steel tie reinforcements. Collapse multipliers are found for different arch-curvatures using monolithic and regular coursed masonry piers. The results indicate the higher vulnerability of circular arches to horizontal forces compared to pointed (gothic) arch forms. The examined strengthening strategy, steel tie-rods, provided prominently better seismic resistance and changed the collapsed mechanism. The effectiveness of tie-rods appeared most on the circular arches with monolithic piers by providing higher resistance to the horizontal loads.

\section{REFERENCES}

Alexakis, H. and Makris, N., 2017. Hinging mechanisms of masonry single-nave barrel vaults subjected to lateral and gravity loads. Journal of Structural Engineering, 143(6), p.04017026 Cundall, P.A. and Hart, R.D., 1995. Numerical modelling of discontinua. In Analysis and Design Methods (pp. 231-243).

Dimitri, R., De Lorenzis, L. and Zavarise, G., 2011. Numerical study on the dynamic behavior of masonry columns and arches on buttresses with the discrete element method. Engineering Structures, 33(12), pp.3172-3188.

Lemos, J.V., 2007. Discrete element modeling of masonry structures. International Journal of Architectural Heritage, 1(2), pp.190-213. 
- This is a pre-print version of an article published in Pulatsu B., Erdogmus E., Bretas E.M. and Lourenço P.B. (2019) In-Plane Static Response of Dry-Joint Masonry Arch-Pier Structures, Architectural Engineering Institute (AEI) Conference, April 3-6. DOI: 10.1061/9780784482261.028

Lengyel, G., 2017. Discrete element analysis of gothic masonry vaults for self-weight and horizontal support displacement. Engineering Structures, 148, pp.195-209.

Lourenço, P. B., 2002. Computations on historic masonry structures. Progress in Structural Engineering and Materials, 4 (3), pp. 301-319.

Peña, F., Lourenço, P.B., Mendes, N. and Oliveira, D.V., 2010. Numerical models for the seismic assessment of an old masonry tower. Engineering Structures, 32(5), pp.1466-1478.

Pulatsu, B., Erdogmus, E. and Bretas, E.M., 2018. Parametric Study on Masonry Arches Using 2D Discrete Element Modeling. Journal of Architectural Engineering, 24(2), p.04018005.

Pulatsu, B., Erdogmus, E. and Lourenco, P.B., 2019. Comparison of in-plane and out-of-plane failure modes of masonry arch bridges using discontinuum analysis. Engineering Structures, pp. 178, 24-36.

Pulatsu, B., Bretas, E.M. and Lourenco, P.B., 2016. Discrete element modeling of masonry structures: Validation and application. Earthquakes and Structures, 11(4), pp.563-582.

Pulatsu, B., Sarhosis, V., Bretas, E.M., Nikitas, N. and Lourenço, P.B., 2017. Non-linear static behaviour of ancient free-standing stone columns. Proceedings of the Institution of Civil Engineers - Structures and Buildings, 170 (6), pp. 406-418. 